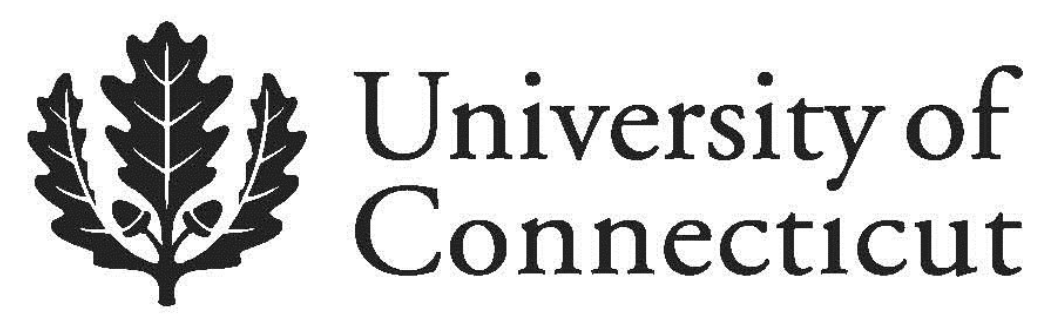

Department of Economics Working Paper Series

\title{
Demographic Transition and Economic Welfare: The Role of In-Cash and In-Kind Transfers
}

Stephen M. Miller

University of Nevada, Las Vegas

University of Connecticut

Kyriakos Neanidis

University of Manchester

Working Paper 2014-24

September 2014

365 Fairfield Way, Unit 1063

Storrs, CT 06269-1063

Phone: (860) 486-3022

Fax: (860) 486-4463

http://www.econ.uconn.edu/

This working paper is indexed on RePEc, http://repec.org 


\title{
Demographic Transition and Economic Welfare: The Role of In-Cash and In-Kind Transfers*
}

\author{
Stephen M. Miller \\ College of Business \\ University of Nevada, Las Vegas \\ 4505 Maryland Parkway \\ Las Vegas, Nevada, USA 89154-6005 \\ stephen.miller@unlv.edu \\ Kyriakos C. Neanidis** \\ Economics \\ Centre for Growth and Business Cycle Research \\ University of Manchester \\ Oxford Road, Manchester M13 9PL \\ United Kingdom \\ kyriakos.neanidis@manchester.ac.uk
}

\begin{abstract}
Do in-cash and in-kind transfers to families affect parental fertility choices and economic welfare differently? We examine this question via a demographic transition channel in the context of a two-period overlapping generations model. In childhood, reproductive agents face a non-zero probability of death, while as adults, they allocate their time to work, leisure, and child rearing activities. Health status in adulthood exhibits "state dependence," as it depends on health in childhood. We find that cash transfers lead to both higher fertility and welfare if parents strongly value the quantity of their children. This positive welfare effect dominates an indirect negative welfare effect due to a lower growth rate. But, if parents value the quality of their children, inkind transfers yield greater welfare, along with lower fertility and higher economic growth.
\end{abstract}

Keywords: fertility; health; growth; transfers; welfare

JEL classification: F35; F43; I12; O41

* We acknowledge the helpful comments of an anonymous referee.

** Corresponding author 


\section{Introduction}

Developing and developed countries implement government transfer programs, as a mechanism of social protection that promotes societal and economic development of the most vulnerable groups of the population (i.e., the children, the old, the poor, and the sick, among others). Although most analysts do not question the importance of government transfers for social inclusion and economic well-being, a debate exists concerning the optimal type of transfers. We can broadly divide the policy interventions dedicated to improving the material welfare of the targeted groups of people into two categories: transfers in cash and in-kind. ${ }^{1}$ The current study contributes to this discussion by comparing the growth and welfare implications of monetary (cash) and in-kind transfers. It tackles this issue in a model with endogenous fertility so that we consider issues that relate to demographic transition. Our findings offer an alternative interpretation regarding the dominance of each type of transfer to those outlined in the literature.

Microeconomic theory generally argues that money transfers leave individuals better off than targeted, in-kind, transfers since individuals allocate the money to their own best use. This means that monetary transfers should leave individuals better off in terms of welfare when compared to in-kind transfers, as the former do not constrain the behavior of the recipients. ${ }^{2}$ In practice, however, we observe widespread and sizeable use of in-kind transfer programs across the world. ${ }^{3}$ This contradiction between traditional theory and observed practice generates a literature that offers competing explanations for the prevalence of in-kind transfers. The rational

\footnotetext{
${ }^{1}$ Transfers in cash include social pensions, unemployment insurance, sickness, maternity, family allowance, and workplace injury benefits. Transfers in-kind consist of either the transfer of particular goods other than cash, or the provision of a service. Typical examples of in-kind transfers are food subsidies, healthcare and medical provision, childcare and public housing.

${ }^{2}$ A detailed analysis of the weak dominance of cash transfers over cost-equivalent in-kind transfers appears, among other sources, in Aaron and Von Fürstenberg (1971).

${ }^{3}$ Currie and Gahvari (2008) report that in the early 2000s the governments of seventeen OECD countries have spent on average more than 12 percent of their GDP on just three in-kind programs combined (health, childcare, and education).
} 
for in-kind transfers include the improved targeting of benefits and self-selection (Nichols and Zeckhauser, 1982), the improved efficiency of the tax system (Munro, 1992), the Samaritan's dilemma (Buchanan, 1975), the presence of pecuniary effects (Coate, 1989), and political economy considerations (De Janvry et al., 1991). A popular explanation, paternalism, involves the conflict between donor (government) and recipient (household) preferences. Since recipients do not calculate the social benefits while donors do, the social benefits from the provision of certain goods and services can provide the rationale for using in-kind transfers. Currie and Gahvari (2008) conclude in their survey of the theory and data on cash and in-kind transfers that paternalism with interdependent preferences provides the best overall explanation of the presence of in-kind transfers in practice. ${ }^{4}$

In parallel to these plausible causal factors of in-kind transfers, a number of studies have examined the effect of government transfers on economic performance. Early work on this subject involved either monetary transfers, or a bundling of all types of transfers into one category. Studies investigated, among others, the effect of transfers on saving, capital accumulation, and growth (Feldstein, 1974; Barro, 1974; Zhang, 1995; Cigno and Rosati, 1996), fertility and human capital (Zhang, 1995; Ehrlich and Lui, 1998; Zhang and Zhang, 2004; Ehrlich and Kim, 2005), income inequality (Aghion and Bolton, 1997; Keane and Prasad, 2002), and longevity (Philipson and Becker, 1998; Zhang et al., 2006).

More recently, a few studies distinguished between monetary and in-kind transfers and evaluated and compared their effects within specific economic environments. Such studies include Gahvari (1994) who compares the effect of cash and in-kind transfers on labor supply, Cunha et al. (2011) who examine their effect on (normal) goods prices in a partially closed

\footnotetext{
${ }^{4}$ See Daly and Giertz (1972), Garfinkle (1973), and Olsen (1980) for earlier studies of paternalism with interdependent preferences. Khera (2014) provides recent empirical support in favor of paternalism for India.
} 
economy, Cunha (2014) who finds that both types of transfers increased children's nutritional intake in Mexico and improved children health by the same margin, and Lieber and Lockwood (2013) who estimate the costs and benefits of providing Medicaid home-care benefits in cash and in-kind. A shortage of research, however, exists in combining both types of transfers with the view of comparing their effects on macroeconomic outcomes, especially economic welfare and the determination of Pareto optimal distributions.

This paper addresses this gap by investigating how monetary and in-kind transfers influence economic growth and welfare via a demographic transition mechanism. Within a twoperiod overlapping generations model with endogenous fertility, government transfers influence parental decisions with regard to the number and the quality of children, in line with the economic model of fertility (Becker, 1960; Galor and Weil, 2000; Chakraborty, 2004). In this view, parents value both the number of their children and their education (or health), and given that both childrearing and education (health) involve costs, a trade-off emerges. As a result, government transfers change the rate of return on human capital, thereby inducing parents to substitute between child quality and quantity. This outcome leads to different rates of fertility and economic growth through human capital accumulation, thus offering a link between demographic and economic transitions. ${ }^{5}$

Our model, by incorporating both in-kind and in-cash transfers, allows the illustration of the multi-faceted effect of social protection programs on welfare. Specifically, endogenizing fertility decisions demonstrates that public transfers do not always improve welfare. In our analysis, both in-kind and monetary transfers affect welfare, with the sign of the effect depending on the parents' preferences toward child quantity (or quality). In-kind transfers lead to higher

\footnotetext{
${ }^{5}$ Moffitt (1997), in a review of numerous studies regarding the effect of welfare programs on fertility in the United States, found mixed results, as did more recent studies (Grogger and Bronas, 2001).
} 
welfare, along with lower fertility and higher growth, only if parents value the quality of their children. If instead, they strongly value the number of children, in-kind transfers diminish welfare. But in this case, monetary transfers yield higher welfare, which coexists with higher fertility and lower growth. Thus, our model generates a condition that determines whether cash or in-kind transfers are welfare-dominant and, in this way, offers an alternative explanation for which of the two types of transfers dominates in terms of the recipient's utility.

As stated earlier, microeconomic theory generally argues that money transfers leave individuals better off than targeted, in-kind transfers. We show that in-kind transfers can also lead to higher growth and social welfare. Thus, our model offers another explanation for the importance of in-kind transfers. Overall, the analysis shows that allocation of public transfers tied to certain activities (in-kind) can produce both positive growth and welfare effects. In this way, policymakers can achieve both improved economic growth and welfare by targeting the types of allocated transfers.

The paper proceeds as follows. Section 2 presents the model. Section 3 solves the model for the equilibrium outcomes of the endogenous variables and derives the expressions for economic growth and welfare. It then determines the effects of changes in monetary and in-kind transfers on economic growth and welfare. Section 4 concludes and describes the implications of our findings for the design of transfer programs.

\section{Model}

Consider a small overlapping generations (OLG) economy, where activity extends over an infinite discrete time period. The economy produces one homogeneous good, which is consumed only in that period, with labor as the single input. Individuals in each generation live (at most) for two periods: childhood and adulthood. Each individual receives one unit of time in childhood 
and two units in adulthood. Children depend on their parents for consumption and healthcare. Adults supply one unit of labor inelastically at a given wage rate, which finances consumption in adulthood and raises children. They use their remaining non-work unit of time to provide childrearing activities and enjoy leisure. ${ }^{6}$ Adult agents also receive support from the government in the form of transfers.

Each adult becomes a parent and bears $n$ children, each of which possess the same innate abilities and the same initial health status. The cost of keeping children healthy, however, involves both the parent's time and spending on marketed goods (food, medicines, etc.).

At birth, children face a non-zero probability of dying, which decreases in the amount of in-kind (food and medical) transfers consumed. The health status of children depends not only on parents' income, but also on the time parents spend in childrearing and on their health status (see Powdthavee and Vignoles, 2008, for health status). Adult health status, in turn, depends linearly on the health status as a child, indicating 'state dependence' in health outcomes (Case et al., 2005).

In addition to individuals, the economy includes firms and an infinitely-lived government. Firms produce marketed goods using labor as an input. The government offers transfer payments to households in two forms, monetary and in-kind. It finances its transfer program by taxing the wage income of adults. It cannot borrow and, therefore, must run a balanced budget in each period. Finally, all markets clear and no debts or bequests occur between generations.

\footnotetext{
${ }^{6}$ The distinction of the adults' time between a unit of work and a non-work unit devoted to childrearing and leisure does not decisively affect our findings. The results carry through if one assumes instead that adults allocate time across all three activities. This would yield a trade-off between time spent on work and leisure that is consistent with most of the studies in the literature. The decision to disentangle work time from leisure time hinges, as will become clear below, on the capacity of child-rearing time to contribute to better health status and higher productivity for future adults. In this way, a trade-off between "productive" and "unproductive" use of time occurs that exhibits similar properties to the division of time between work and leisure.
} 


\section{Households}

Let $N_{t}$ equal the number of adults in period $t$, with each adult bearing $n_{t}$ children. At the beginning of period $t$, the probability that a child survives to adulthood equals $p_{t} \in(0,1)$. For tractability, the number of surviving children equals the expected number of survivors. To avoid convergence of population to zero, we assume that $p_{t} n_{t} \geq 1$, which implies a positive population growth rate. Raising a child involves two costs, spending $\varepsilon_{t+1} \in(0,1)$ units of time on each child's health care, which implies the allocation of $\varepsilon_{t+1} n_{t+1}$ units of time, and spending a fraction $\theta \in(0,1)$ of adult income on each child's health, which implies foregone wage income and consumption.

Let $y_{t+1}$ denote the individual's income in $t+1$. Thus, the total cost of raising $n_{\mathrm{t}+1}$ children, if all survive, equals the sum of the opportunity cost in terms of foregone wage earnings and the opportunity cost in terms of foregone consumption, that is, $\left(\varepsilon_{t+1}+\theta\right) n_{t+1} y_{t+1}$. Thus, as is standard in the literature (Barro and Becker, 1989; Galor and Weil, 2000), these costs create a trade-off between the quality and quantity of children. This cost, however, is not with respect to education, but with respect to health.

Including the consumption of children in their parents' consumption, lifetime utility at the beginning of period $t+1$ of a (surviving) agent born at $t$ is specified as follows:

$$
U_{t+1}=\ln \left(c_{t+1}^{t}\right)+\eta_{L} \ln \left(1-p_{t+1} n_{t+1} \varepsilon_{t+1}\right)+\eta_{N} \ln \left(p_{t+1} n_{t+1} h_{t+1}^{C}\right)
$$

where $U_{t+j}$ and $c_{t+j}^{i}$ denote the utility and consumption of generation $i$ individuals at date $t+\mathrm{j}$ and ln equals the natural logarithm operator. The term $\left(1-p_{t+1} n_{t+1} \varepsilon_{t+1}\right)$ measures leisure in adulthood, whereas coefficients $\eta_{L}$ and $\eta_{N}$ measure the individual's relative preference for leisure and surviving healthy children. The term $\left(p_{t+1} n_{t+1} h_{t+1}^{C}\right)$ equals actual family size $\left(p_{t+1} n_{t+1}\right)$, which 
differs from fertility, $n_{\mathrm{t}+1}$, since the child survival rate is less than one, multiplied by the health status of a child, $h_{t+1}^{C}$. In the standard literature, parents derive utility from the 'raw' production of offspring. Here, however, the expected number of healthy children matters.

Assuming that child mortality occurs only at the beginning of the period, parents incur no childrearing costs for children who die. ${ }^{7}$ Because children's consumption is subsumed in their parent's consumption so that no independent consumption in childhood exists, the periodspecific budget constraint is as follows:

$$
c_{t+1}^{t}=\left(1-\theta p_{t+1} n_{t+1}-\tau\right) \alpha_{t+1} w_{t+1}+M_{t+1} \frac{n_{t+1}}{N_{t+1}} .
$$

where $\alpha_{t+1}$ is individual labor productivity, $w_{t+1}$ denotes the real wage rate, and $\tau \in(0,1)$ is the effective-wage tax rate. Each household receives monetary transfers from the government, indicated by $M_{\mathrm{t}+1}$, proportional to the number of children per household, $n_{\mathrm{t}+1} / N_{\mathrm{t}+1}$, so that, total monetary transfers equal $M_{\mathrm{t}+1} n_{\mathrm{t}+1} / N_{\mathrm{t}+1} \cdot{ }^{8}$ Linking cash transfers to the number of children per family aims to improving their nutritional levels since they represent the most vulnerable group of the population.

Note that although $\theta$ itself is not a decision variable, it could be made a function of transfers. Such transfers could lead parents to spend a smaller fraction of their labor income on children's rearing and induce a crowding out effect. This would offer yet another channel through

\footnotetext{
${ }^{7}$ Alternatively, we could assume that parents incur childrearing costs for all children, regardless of whether they survive or not. The assumption in the text seems more natural, given that in many poor countries mortality in childhood tends to occur early in the life of children.

${ }^{8}$ In other words, each child receives this transfer to increase its likelihood of survival. That is, monetary payments are received by all children, whether they subsequently survive or not.
} 
which government transfers may affect fertility and growth. For simplicity, however, $\theta$ is kept constant. $^{9,10}$

\section{Firms}

We assume a simple technology where aggregate output is given by

$$
Y_{t}=A_{t} N_{t},
$$

where $A_{t}$ denotes each firm's common, average, economy-wide labor productivity and $N_{t}$ denotes the number of adult workers employed. Thus, production exhibits constant returns to scale in effective labor $A_{t} N_{t}$, which gives rise to endogenous growth in the steady state.

\section{Health status and productivity}

Following Neanidis (2012), the health status of a child, $h_{t}^{C}$, depends on goods purchased out of parents' income, the parent's health status, $h_{t}^{A}$, and the time allocated by their parent to rearing them:

$$
h_{t}^{C}=\theta\left(h_{t}^{A}\right)\left(\varepsilon_{t}\right)^{v},
$$

where $v \in(0,1)$ is an efficiency parameter. First, a child's health status is linear in the share of resources spent by the parent, $\theta$, because it improves a child's health and nutrition, thereby reducing the child's vulnerability to disease (Pelletier et al., 2003; Caulfield et al., 2004). Second, a child's health depends on the parent's health, which may relate to the effect of parents' mental distress and anxiety on children’s life satisfaction (Larson and Gillman, 1999; Downey et

\footnotetext{
${ }^{9}$ This assumption receives support from recent evidence that estimates a relatively small share of household income used for children expenditure. According to Bargain and Donni (2012), in France the overall cost of household income expenditure on a boy is just $5.3 \%$, while it is much lower for a girl, standing at $0.4 \%$.

${ }^{10}$ Generally speaking, another type of crowding out effect of government transfers could occur on the decision of agents to supply their labor time. That is, transfer programs may crowd out the agent's working efforts. In this model, however, the adult's working time is fixed, so the crowding out effect operates through the allocation of the adult's time between leisure and caring for her children's health. The implications of the crowding out effect are qualitatively similar, though, given the importance of health for labor productivity. Since the time devoted to child health care contributes to future health and labor productivity, government transfers crowd out output and wages via labor productivity rather than the adult's working effort.
} 
al., 1999) and their physical ability to take care of their children. It may also reflect Barker's (1998) 'foetal origins hypothesis', which suggests that conditions in utero may exert long-lasting effects on an individual's health (see, for evidence, Almond, 2006 and the survey by Almond and Currie, 2011). Third, the health status of a child depends on the time allocated to the child by the parent. ${ }^{11}$

To capture the idea, established by recent work, that events in early life can exert large long-term effects on adult outcomes, we assume that the health status of adults depends only on health status in childhood. Studies that support this link include Fogel (1994), Strauss and Thomas (1998), Case, et al. (2002) and, more recently, the surveys by Behrman (2009) and Currie (2009). As a result, health status displays persistence, as in Osang and Sarkar (2008). Given this evidence, we specify

$$
h_{t+1}^{A}=h_{t}^{C} .
$$

Substituting (5) into (4) yields

$$
h_{t+1}^{A}=\theta\left(h_{t}^{A}\right)\left(\varepsilon_{t}\right)^{v} .
$$

Thus, because a parent's health affects the children's health, and because adult well-being depends on own health in childhood, serial dependence exists in $h_{t}^{A}$. This specification conforms to Grossman (1972), who views health as a durable stock, which increases here with more spending on goods but also with more time taking care of one’s children.

In line with the empirical evidence, and the specification in Neanidis (2012), we assume that adult productivity depends linearly on health status:

\footnotetext{
${ }^{11}$ The linearity of the child's health status on parent's health does not carry any important implications for the solution of the model. If, instead, children's health exhibited diminishing returns it would reinforce the role of childrearing time on economic growth and imply that the health status is constant at the balanced growth path. For a model where children's health status exhibits diminishing returns to parent's health status, see Neanidis and Papadopoulou (2013).
} 


$$
\alpha_{t}=h_{t}^{A}
$$

\section{Government}

The government obtains revenue by applying a constant tax rate $\tau$ on the effective wage of adult agents and spends a total of $T_{t}$ on transfer payments to households. ${ }^{12}$ Transfer payments, in turn, take two forms, monetary, $M$, and in-kind, $F{ }^{13}$ As the government cannot issue bonds, it must run a balanced budget:

$$
T_{t}=M_{t}+F_{t}=N_{t} \tau A_{t} w_{t}
$$

We model the shares of government spending as constant fractions of revenue:

$$
\begin{aligned}
& M_{t}=m N_{t} \tau A_{t} w_{t}, \quad \text { and } \\
& F_{t}=f N_{t} \tau A_{t} w_{t},
\end{aligned}
$$

where $m, f \in(0,1)$. Combining (8)-(10), therefore, yields:

$$
m+f=1 .
$$

Equations (8)-(10) illustrate that, in addition to monetary transfers, households receive

for each child in-kind assistance in the form of food, healthcare, and medical goods, $F_{\mathrm{t} .}{ }^{14} \mathrm{~A}$ series of studies show that this type of transfer plays a vital role in saving children's lives by limiting nutritional distress and minimizing the risk of death. For instance, Currie and Gruber (1996) illustrate that extending public health insurance to uncovered infants and children

\footnotetext{
${ }^{12}$ The government announces the tax rate at the beginning of time and commits fully and credibly to it. In this way, no fundamental time-consistency problem exists.

${ }^{13}$ We could adopt another type of government spending in the form of health expenditure that would directly increase health status and adult productivity. This consideration, however, would not affect the agent's optimal choices in equilibrium, other than complicate the determination of the economic growth rate. In addition, it would unnecessarily divert attention from the main theme of the paper. For these reasons, we prefer analytical tractability and opt out from this type of spending (see Neanidis and Papadopoulou, 2013).

${ }^{14}$ Note that in-kind transfers do not involve any cash transfers, that is, recipients cannot resell their allotments. In this way, the former do not belong to a budget constraint as long as the household does not sell these goods to generate revenue, an activity that we abstract from. We use the monetary equivalent of in-kind transfers for comparison purposes with monetary transfers.
} 
significantly improved their health; Gertler (2000) and Behrman and Hoddinott (2001) estimate that the nutritional component of the Progresa program in Mexico exhibits positive effects on child health and growth; Stifel and Alderman (2006) report that nutritional supplements in Peru under the Vaso de Leche (“Glass of Milk”) program, targeted to children aged three to eleven, results in positive child health outcomes; similarly, for a developed country, the United States' Supplemental Feeding Program for Women, Infants, and Children produces sizeable improvements in infant health (Currie and Gahvari, 2008). ${ }^{15}$ This evidence supports the notion that in-kind transfers increase the likelihood $\left(p_{t}\right)$ of a child's survival to adulthood. We, thus, model the probability of survival as depending on the fraction of income allocated to in-kind transfers as follows: $p_{t}(f)$ with $p_{t}^{\prime}(f)>0 .^{16}$

\section{Long-run equilibrium, choice of time and fertility, and macroeconomic dynamics}

This section determines the long-run equilibrium outcomes for fertility, the time allocated to childrearing, economic growth, and welfare. Then, we explicitly determine the effects of in-kind and monetary transfers on these equilibrium outcomes.

\section{Equilibrium solutions}

The discussion begins with the definition of a competitive equilibrium:

Definition 1. A competitive equilibrium for this economy is a sequence of prices $\left\{w_{t}\right\}_{t=0}^{\infty}$, allocations $\left\{c_{t+1}^{t}, \varepsilon_{t+1}\right\}_{t=0}^{\infty}$, health status of children and adults $\left\{h_{t}^{C}, h_{t}^{A}\right\}_{t=0}^{\infty}$, and a constant tax rate $\tau$ and constant spending shares $m, f$, such that, given the initial health statuses $h_{0}^{C}>0$ and

\footnotetext{
${ }^{15}$ Studies within the foreign aid literature also support the importance of in-kind aid transfers to low-income countries for extending and improving children's lives, especially by limiting mortality rates associated with diseases such as measles and diarrhea (e.g., De Waal, et al., 2006; Center for Global Development, 2007; Plumber and Neumayer, 2009).

${ }^{16}$ It may seem more appropriate to link the probability of survival to the total amount of in-kind transfers received (i.e., $F_{t}$ ). Our results, however, do not depend on this assumption, which, as will become clear below, simplifies the comparison between the quantitative effects of the two types of public transfers.
} 
$h_{0}^{A}>0$, individuals maximize utility, firms maximize profits, markets clear, and the government budget balances.

In equilibrium, individual productivity equals the economy-wide average productivity, so that $\alpha_{t}=A_{t}$. In addition, we simplify and assume that children of each generation face an identical probability of survival to adulthood. That is, $p_{t}(f)=p_{t+1}(f)=p(f)$. This assumption leads to the definition of the balanced growth path as follows:

Definition 2. A balanced growth equilibrium is a competitive equilibrium in which $c_{t}^{t}, c_{t+1}^{t}, h_{t}^{C}, h_{t}^{A}$ and $\left(Y_{t} / N_{t}\right)$, all grow at the constant endogenous rate $1+\gamma$.

Each adult maximizes equation (1) subject to equations (2) and (6), with respect to $C_{t+1}^{t}$, $\mathcal{E}_{t+1}$, and $n_{t+1}$, taking $\tau, p(f)$, and $M_{\mathrm{t}+1}$ as given. ${ }^{17}$ Remembering that $\alpha_{t}=A_{t}$ in equilibrium, solving the model yields the following solutions for fertility, child rearing time, and per capita growth respectively:

$$
\begin{aligned}
& \tilde{n}=\frac{\eta_{N}(1-v)(1-\tau)}{[\theta p(f)-m \tau]\left[1+\eta_{N}(1-v)\right]}, \\
& \tilde{\varepsilon}=\Lambda\left\{\frac{[\theta p(f)-m \tau]\left[1+\eta_{N}(1-v)\right]}{p(f) \eta_{N}(1-v)(1-\tau)}\right\}, \text { and } \\
& 1+\gamma=\theta\left\{\Lambda \frac{[\theta p(f)-m \tau]\left[1+\eta_{N}(1-v)\right]}{p(f) \eta_{N}(1-v)(1-\tau)}\right\},
\end{aligned}
$$

\footnotetext{
${ }^{17}$ The solution to the household problem follows closely the derivation in Appendix A in Neanidis (2012).
} 
where $\Lambda \equiv \eta_{N} v /\left(\eta_{L}+\eta_{N} v\right) .{ }^{18}$ We impose the following two assumptions to ensure (i) positive values for the equilibrium solutions, and (ii) that the population size does not converge to zero $(p(f) \tilde{n} \geq 1)$, respectively. That is,

Assumption 1: $p(f)>\frac{m \tau}{\theta}$; and

Assumption 2: $\frac{\theta p(f)-m \tau}{p(f)} \leq \frac{\eta_{N}(1-v)(1-\tau)}{1+\eta_{N}(1-v)} \equiv \Gamma$

The first assumption requires that the fraction of income received as monetary transfer is small compared to the fraction of income spent on caring for each child, while the second assumption requires that the latter amount is not too large either.

Equation (14) implies that the model exhibits no transitional dynamics. Following a shock, the time adults allocate to child rearing jumps immediately to its new equilibrium value, where it stays thereafter. In addition, the health status of both adults and children grow at the same constant rate. It then follows that the economy is always on its balanced growth path.

Implications of changes in transfers for fertility, time allocation, and growth

Equations (12)-(14) determine the steady state fertility rate, time allocation to child rearing, and growth rate, respectively. We now consider the effects of changes in government transfers on the steady-state equilibrium. More specifically, we consider the effect of changes in in-kind and monetary transfers on the fertility rate, the time allocation to child rearing, and the growth rate. An increase in in-kind transfers means an increase in $f$, while an increase in monetary transfers means an increase in $m$, which correspond to the exogenous components of these types of

\footnotetext{
${ }^{18}$ We can easily show that $p(f) \tilde{n} \tilde{\varepsilon}=\Lambda<1$, which implies a feasible time allocation with positive leisure in equilibrium.
} 
transfers (see equations (9) and (10)). Thus, from equations (12) and (13), we can derive the following outcomes, used to establish Proposition 1:

$$
\begin{aligned}
& \frac{d \tilde{n}}{d f}=-\frac{\Gamma \theta p^{\prime}(f)}{[\theta p(f)-m \tau]^{2}}<0 ; \quad \frac{d \tilde{n}}{d m}=\frac{\Gamma \tau}{[\theta p(f)-m \tau]^{2}}>0, \\
& \frac{d \tilde{\varepsilon}}{d f}=\frac{p^{\prime}(f) m \tau \Lambda}{[p(f)]^{2} \Gamma}>0 ; \quad \frac{d \tilde{\varepsilon}}{d m}=-\frac{\tau \Lambda}{p(f) \Gamma}<0,
\end{aligned}
$$

Proposition 1. An increase in government transfers in the form of in-kind (monetary) transfers reduces (increases) fertility and increases (reduces) parents' childrearing time for each child.

In-kind transfers exert a negative effect on fertility by increasing the probability of survival from childhood to adulthood. The fact that the fertility rate inversely relates to the survival probability conforms to Kalemli-Ozcan (2003), who explicitly considers in a stochastic framework ex ante uncertainty about the number of surviving children. Higher mortality increases the number of births beyond the number required to produce the desired and expected number of survivors. As mortality rates, and thus uncertainty, fall, the precautionary demand for children also decreases. Neanidis (2012) provide evidence that supports this view. He shows that a decline in infant mortality (a proxy for higher child survival rate) decreases the fertility rate. Monetary transfers, on the other hand, increase fertility by reducing the 'quantity cost' of children, thereby shifting resources from children's quality to their quantity. Therefore, monetary transfers increase the return on child quantity, a finding supported by empirical evidence from Canada (Milligan, 2005), France (Laroque and Salanie, 2008), and the UK (Brewer et al., 2012).

The effect of government transfers on parents' childrearing time also works in conflicting directions. In-kind transfers exert a positive effect on the time allocated to childrearing for each child as a consequence of the lower number of children. Thus, parents spend more time on each of their children. Monetary transfers proportional to the number of born children, on the other 
hand, induce parents to decrease their childrearing time for each child as their expected (monetary) gain for each born child rises.

From equation (14), we can derive the effect of public transfers on long-run growth, which is summarized in Proposition 2:

$$
\frac{d(1+\gamma)}{d f}=\frac{(1+\gamma) v}{[\theta p(f)-m \tau]} \frac{p^{\prime}(f) m \tau}{p(f)}>0 ; \quad \frac{d(1+\gamma)}{d m}=-\frac{(1+\gamma) v \tau}{[\theta p(f)-m \tau]}<0 .
$$

Proposition 2. An increase in government transfers in the form of in-kind (monetary) transfers exerts a positive (negative) effect on growth.

The increase in public transfers produces an unclear effect on the economic growth rate because of the opposing effects of in-kind and monetary transfers per child. In-kind transfers exert a positive effect on growth by directly enhancing the health status of surviving children and their productivity during adulthood. Monetary transfers per child, on the other hand, reduce the childrearing time that adults allocate to their children, which lowers children's health status. This, in turn, reduces health status in adulthood, and subsequently the rate of economic growth. The ambiguous effect of government transfers on growth finds support in the empirical literature, which produces mixed findings. Without drawing a distinction between in-cash or in-kind transfers, studies exist that support a positive growth effect of transfers (Zhang and Zhang, 2004; Perotti, 2006), while others support a negative effect (Hansson and Henrekson, 1994; Ehrlich and Zhong, 1998, Ehrlich and Kim, 2005).

Although our analytical findings demonstrate the ambiguity of the effects of transfer programs, we can derive the conditions under which the effects of one type of transfers dominate the other. Since the effects of in-kind and monetary transfers exhibit opposite signs, we take the absolute value of the ratios of the partial derivatives with respect to in-kind and monetary transfers, described in equations (15) through (17). The following expressions result: 


$$
\begin{aligned}
& \left|\frac{\frac{d \tilde{n}}{d f}}{\frac{d \tilde{n}}{d m}}\right|=\frac{\theta p^{\prime}(f)}{\tau} \text {, and } \\
& \left|\frac{\frac{d \tilde{\varepsilon}}{d f}}{\mid \frac{d \tilde{\varepsilon}}{d m}}\right|=\left|\frac{\frac{d(1+\gamma)}{d f}}{\frac{d(1+\gamma)}{d m}}\right|=\frac{p^{\prime}(f) m}{p(f)} .
\end{aligned}
$$

Equation (18) implies that, in absolute magnitude, the effect of in-kind transfers on equilibrium fertility dominates that of monetary transfers, when the marginal effect of in-kind transfers on the probability of survival to adulthood is sufficiently large, $p^{\prime}(f)>\tau / \theta$. Otherwise, monetary transfers exhibit a quantitatively greater effect on steady-state fertility.

Equation (19) leads to the following result:

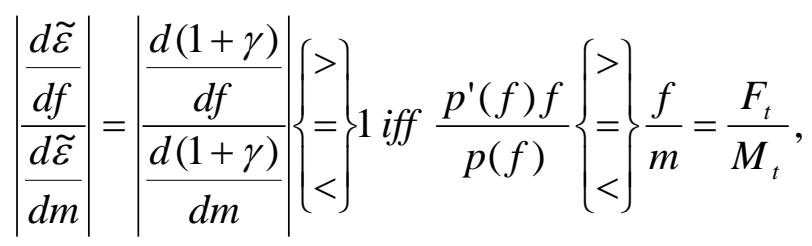

remembering that in-kind and monetary transfers are proportional to total government revenue (see equations (9) and (10)). Further, Assumption 1 implies the following relationship between equations (18) and (19):

$$
\left|\frac{\frac{d \tilde{\varepsilon}}{d f}}{\frac{d \tilde{\varepsilon}}{d m}}\right|=\left|\frac{\frac{d(1+\gamma)}{d f}}{\frac{d(1+\gamma)}{d m}}\right|<\left|\frac{\frac{d \tilde{n}}{d f}}{\frac{d \tilde{n}}{d m}}\right| .
$$

Intuitively, condition (20) suggests that the magnitude of the effect of in-kind transfers on parent's childrearing time and economic growth exceeds (falls below) the effect of monetary transfers when the elasticity of the probability of a child's survival into adulthood with respect to in-kind transfers exceeds (falls below) the ratio of in-kind transfers to monetary transfers This 
implies that a distribution of a transfer program between in-kind and monetary forms can achieve a desired increase in economic growth as long as the elasticity of a child's survival likelihood with respect to in-kind transfers is sufficiently high. For instance, if the proportion of total transfers given in in-kind form is low compared to its monetary counterpart (i.e., a small $F / M$ ), as long as the survival probability greatly responds to the rise in in-kind transfers, then the overall growth effect of the transfer program is positive. If, on the other hand, the responsiveness is low, even a much higher size of in-kind transfers compared to money transfers will not be sufficient to preclude a decline in economic growth.

The above, then, imply that domestic policy makers can design transfer distribution programs to increase economic growth by comparing the allocation of transfers into its in-kind and monetary types to how responsive the children's survival rate is to in-kind transfers. As long as this responsiveness is high, even a small amount of in-kind transfers can put the recipient on a path of higher economic growth.

Implication of changes in transfers for welfare

As discussed earlier, paternalistic arguments appear to represent the best justification for the prevalence of in-kind transfers (see Currie and Gahvari, 2008). As is illustrated below, however, our model offers an alternative explanation for the dominance of in-kind transfers. At the same time, it does not preclude the likelihood that cash transfers can be superior. The outcome as to which of the two types of transfers dominates in terms of the recipient's utility depends on a condition that incorporates the weight parents attach to the number of surviving healthy children in their utility $\left(\eta_{N}\right)$ and the health-related efficiency of the time allocated to rearing their children $(v)$. Thus, in contrast to standard economic theory, under certain 
conditions, welfare produced with targeted, in-kind transfers by government distribution programs exceeds the welfare garnered by cash transfers.

The analysis giving rise to this result is as follows. Substitute equations (2), (7), and (9) into the utility function, equation (1), to get

$$
\begin{aligned}
U_{t+1}=\ln \left\{\left[1-\theta p_{t+1}(f) n_{t+1}-\tau+m m_{t+1}\right] h_{t+1}^{A} w_{t+1}\right\} & \\
& +\eta_{L} \ln \left[1-p_{t+1}(f) n_{t+1} \varepsilon_{t+1}\right]+\eta_{N} \ln \left[p_{t+1}(f) n_{t+1} h_{t+1}^{C}\right] .
\end{aligned}
$$

Using equation (5), and expanding parts of the terms in natural logarithms, we see that

$$
\begin{aligned}
U_{t+1}=\ln \left\{\left[1-\theta p_{t+1}(f) n_{t+1}-\tau+m \tau n_{t+1}\right] w_{t+1}\right\}+\ln h_{t+1}^{A} \\
+\eta_{L} \ln \left[1-p_{t+1}(f) n_{t+1} \varepsilon_{t+1}\right]+\eta_{N} \ln \left[p_{t+1}(f) n_{t+1}\right]+\eta_{N} \ln h_{t+2}^{A} .
\end{aligned}
$$

Combining equations (4) and (14) leads to the following backward induction:

$$
\ln h_{t+1}^{A}+\eta_{N} \ln h_{t+2}^{A}=\ln \left[\left(h_{0}^{A}\right)^{1+\eta_{N}}(1+\gamma)^{(t+1)\left(1+\eta_{N}\right)+\eta_{N}}\right],
$$

where, as noted earlier, $h_{0}^{A}>0$ is the initial adult health status. Substituting equation (24) into equation (23), along with the assumption that $p_{t}(f)=p_{t+1}(f)=p(f)$, and the result that in the steady-state equilibrium, $w_{t+1}=1, n_{t+1}=\tilde{n}$, and $\varepsilon_{t+1}=\tilde{\varepsilon}$, leads to the following relationship

$$
\begin{aligned}
& \tilde{U}=\ln \{(1-\tau)-[\theta p(f)-m \tau] \tilde{n}\}+\eta_{L} \ln [1-p(f) \tilde{n} \tilde{\varepsilon}] \\
&+\eta_{N} \ln [p(f) \tilde{n}]+\left(1+\eta_{N}\right) \ln \left(h_{0}^{A}\right)+\left[(t+1)\left(1+\eta_{N}\right)+\eta_{N}\right] \ln (1+\gamma) .
\end{aligned}
$$

Now, substitute into equation (25) the steady-state values for the fertility rate and the time spent childrearing from equations (12) and (13), respectively, to get after some simplifications

$$
\begin{aligned}
\tilde{U}=\ln & \left\{\frac{1-\tau}{1+\eta_{N}(1-v)}\right\}+\eta_{L} \ln \left\{\frac{\eta_{L}}{\eta_{L}+\eta_{N} v}\right\} \\
& +\eta_{N} \ln \left\{\frac{p(f) \eta_{N}(1-v)(1-\tau)}{[\theta p(f)-m \tau]\left[1+\eta_{N}(1-v)\right]}\right\} \\
& +\left(1+\eta_{N}\right) \ln \left(h_{0}^{A}\right)+\left[(t+1)\left(1+\eta_{N}\right)+\eta_{N}\right] \ln (1+\gamma) .
\end{aligned}
$$


Differentiation of equation (26) with respect to $f$ and $m$ gives rise to the welfare effects of in-kind and monetary transfers, respectively. The effects of transfers emerge from the third and fifth terms on the right-hand side of equation (26), as the remaining terms are constant. The following result holds, summarized in Proposition 3:

$$
\begin{aligned}
& \frac{d \tilde{U}}{d f}=\frac{p^{\prime}(f) m \tau}{p(f)[\theta p(f)-m \tau]}\left\{\left[(t+1)\left(1+\eta_{N}\right)+\eta_{N}\right] v-\eta_{N}\right\} \text {, and } \\
& \frac{d \tilde{U}}{d m}=-\frac{\tau}{[\theta p(f)-m \tau]}\left\{\left[(t+1)\left(1+\eta_{N}\right)+\eta_{N}\right] v-\eta_{N}\right\} .
\end{aligned}
$$

Proposition 3. An increase in government transfers of either form, in-kind or monetary, exerts an ambiguous effect on welfare.

Either type of transfers may increase or decrease welfare. In-kind transfers decrease the number of children (family size) as they raise their likelihood of survival to adulthood. Given that parents value children, however, a decline in their numbers diminishes welfare. At the same time, in-kind transfers enhance growth by raising the amount of time parents allocate to their children. As higher growth exerts a positive effect on welfare (see equation (26)), so do in-kind transfers. Monetary-per-child transfers, on the other hand, produce exactly the opposite effects. Monetary transfers raise the optimal number of children, as parents prefer the quantity of children rather than their quality, thus, raising welfare. But through the negative effect monetary transfers exert on growth, by decreasing the time parents allocate to offspring, they diminish welfare.

Equations (27) and (28) illustrate that a single condition determines which of the two offsetting effects, of both types of transfers, dominates the other. This is shown as follows:

$$
\frac{d \tilde{U}}{d f}>0 \text { and } \frac{d \tilde{U}}{d m}<0 \text {, if }(t+1)\left(1+\eta_{N}\right) v>\eta_{N}(1-v)
$$




$$
\frac{d \tilde{U}}{d f}<0 \text { and } \frac{d \tilde{U}}{d m}>0 \text {, if }(t+1)\left(1+\eta_{N}\right) v<\eta_{N}(1-v)
$$

Intuitively, we can rewrite this condition in terms of how much individuals value the number of surviving healthy children $\left(\eta_{N}\right)$ or in terms of the elasticity of health status with respect to the time individuals allocate to rearing their children $(v)$. If $\eta_{N}$ is relatively low, or $v$ relatively high, in-kind transfers generate a positive welfare effect while monetary transfers exert a negative welfare effect. In contrast, if $\eta_{N}$ is relatively high, or $v$ relatively low, in-kind transfers exert a negative welfare effect while monetary transfers induce a positive welfare effect. The threshold values of $\eta_{N}$, or $v$, are:

$$
\begin{aligned}
& \eta_{\mathrm{N}}=\frac{(t+1) v}{1-(t+2) v}, \\
& v=\frac{\eta_{N}}{\eta_{N}+(t+1)\left(1+\eta_{N}\right)} .
\end{aligned}
$$

The interpretation is as follows. If individuals strongly value the quantity of children, giving monetary transfers for every child induces more children. The welfare effect of money transfers is positive even if an indirect negative welfare effect takes place through lower growth rates. But, if individuals value the quality of their children (health status), they will obtain greater utility by in-kind transfers. Based on these results, government policymakers could raise the household's welfare by designing a transfer distribution program that considers parents' preferences toward the number of children. ${ }^{19}$

\footnotetext{
${ }^{19}$ One may also consider the situation where the government exhibits different preferences than the households with regard to the number of children. In this case, government policymakers could undertake policies to alter the preferences of their population to match those of the government. This would correspond to the case of interdependent preferences between recipients and providers advanced by Daly and Giertz (1972) and Garfinkel (1973). This issue, however, lies outside the focus of this study, where preferences are viewed as given.
} 
Finally, the relative magnitude of the welfare effects of in-kind and monetary transfers is determined as follows:

$$
\left|\frac{\frac{d \tilde{U}}{d f}}{\frac{d \tilde{U}}{d m}}\right|=\frac{p^{\prime}(f) m}{p(f)}
$$

which implies

$$
\left.\left|\begin{array}{l}
\frac{d \tilde{U}}{d f} \\
\frac{d \tilde{U}}{d m}
\end{array}\right| \begin{array}{l}
> \\
= \\
<
\end{array}\right\} \text { iff } \frac{p^{\prime}(f) f}{p(f)}\left\{\begin{array}{l}
> \\
= \\
<
\end{array}\right\} \frac{f}{m}=\frac{F_{t}}{M_{t}} .
$$

This condition appeared in equation (20) when we described the effects of in-kind and monetary transfers on time spent in childrearing and on economic growth. The interpretation is similar here. The magnitude of the effect of in-kind transfers on equilibrium welfare exceeds (falls below) the effect of monetary transfers when the elasticity of the probability of a child's survival into adulthood with respect to in-kind transfers exceeds (falls below) the ratio of in-kind to monetary transfers. In other words, in-kind transfers can enhance welfare as long as the children's survival rate responds sufficiently to this type of transfers. This result illustrates that our model offers another explanation for the potential dominance of in-kind transfers compared to monetary transfers, as reflected in the actual data, beyond paternalism and interdependent preferences between the government and the households.

\section{Concluding remarks}

This paper examines how government transfer programs may affect demographic transition and economic welfare. The programs can take two forms, in-kind transfers versus monetary transfers, consistent with the actual distribution of assistance funds by governments. The analysis in this 
paper illustrates the complexity of the channels and the ambiguity of the effects of transfer programs.

Our study utilizes a two-period OLG model with endogenous fertility, where agents live (at most) for two periods: childhood and adulthood. As agents, parents decide how to allocate their time between leisure and childrearing activities, with the latter improving the health status of children. This, in turn, enhances future adult labor productivity. Government transfers, in-kind and monetary, improve children health status. In-kind transfers increase a child's likelihood of survival to adulthood, while monetary transfers directly contribute to parent's income as a way of financing spending on children's health. In this environment, we assess the fertility, growth and welfare effect of transfer programs by examining independently each of its two forms.

The analysis arrives at the following conclusions. In-kind transfers lead to more time allocated to childrearing and higher economic growth, as well as lower fertility. At the same time, they lead to higher welfare only if parents place a low relative weight on the number of children. In the opposite case, welfare diminishes. The effects of monetary transfers go in the opposite direction. Higher cash transfers raises fertility while they lower childrearing time and economic growth. The influence on welfare depends, once again, on parent's attitude toward child quantity. If parents prefer more children, monetary transfers lead to higher welfare. In the opposite case, welfare diminishes.

In terms of transfer distribution programs, our results have two important qualifications. Firstly, since transfers affect fertility, growth and welfare, policymakers can use such transfers for policy considerations. This is in addition to, what is called productive types of government expenditure (i.e., on education, health, infrastructure, etc.), the effects of which have dominated the public economics literature. Secondly, the allocation of government transfers between its two 
components, in-kind and monetary, plays a crucial role in the way they feed through the economy. This distinction can assist governments to design transfer schemes to achieve their objectives.

According to our results, if the main objective is to achieve demographic transition and raise economic growth, then a transfers program should include in-kind transfers, as long as the elasticity of the children's survival probability with respect to in-kind transfers exceeds the ratio of in-kind to monetary transfers. If the aim is to increase welfare, however, then the transfers program must consider the population's preferences toward children quantity (or quality) as both types of transfers can generate higher welfare. Specifically, policymakers can achieve both higher economic growth and welfare with in-kind transfers, as long as recipients attach a relatively low value on the number of children. 


\section{References}

Aaron, H.J., and Von Furstenberg, G.M., (1971). The inefficiency of transfers in kind: The case of housing assistance. Western Economic Journal 9(2), 184-91.

Aghion, P., and Bolton, P., (1997). A trickle-down theory of growth and development with debt overhang. Review of Economic Studies 64(2), 151-162.

Almond, D., (2006). Is the 1918 influenza pandemic over? Long-term effects of in utero influenza exposure in the post-1940 U.S. population. Journal of Political Economy 114, $672-712$.

Almond, D., and Currie, J., (2011). Human capital development before age five. Handbook of Labor Economics 4B, Chapter 15, 1315-1486.

Bargain, O., and Donni, O., (2012). Expenditure on children: a Rothbarth-type method consistent with scale economies and parents’ bargaining. European Economic Review 56, 792-813.

Barker, D. J. P., (1998). Mothers, Babies and Health in Later Life. 2nd ed. Edinburgh: Churchill Livingston.

Barro, R.J., (1974). Are government bonds net wealth? Journal of Political Economy 82(6), 1095-1117.

Barro, R. J., and Becker, G. S., (1989). Fertility choice in a model of economic growth. Econometrica 57, 481-501.

Becker, G. S., (2007). Health as human capital: synthesis and extensions. Oxford Economic Papers 59, 379-410.

Becker, G. S., (1960). An economic analysis of fertility. In NBER, Demographic and Economic Change in Developed Countries, National Bureau Conference Series no. 10. Princeton, NJ: Princeton University Press.

Behrman, J. R., (2009). Early life nutrition and subsequent education, health, wage, and intergenerational effects. In Health and Growth, ed. by Michael Spence and Maureen Lewis, Washington DC: World Bank.

Behrman, J. R., and Hoddinott, J., (2001). An evaluation of the impact of PROGRESA on preschool child height. International Food Policy Research Institute, Food Consumption and Nutrition Division, Discussion Paper 104.

Brewer, M., Ratcliffe, A., and Smith, S., (2008). Does welfare reform affect fertility? Evidence from the UK. Journal of Population Economics 25(1), 245-66. 
Buchanan, J.M., (1975). The Samaritan's dilemma. In Altruism, Morality, and Economic Theory, ed. Edmund Phelps, 71-85. New York: Russell Sage.

Case, A., Fertig, A., and Paxson, C., (2005). The lasting impact of childhood health and circumstance. Journal of Health Economics 24, 365-89.

Case, A., Lubotsky, D., and Paxson, C., (2002). Economic status and health in childhood: the origins of the gradient. American Economic Review 92, 1308-1334.

Caulfield, L. E., De Onis, M., Bloessner, M., and Black, R. E., (2004). Undernutrition as an underlying cause of child deaths associated with diarrhea, pneumonia, malaria, and measles. American Journal of Clinical Nutrition 80, 193-198.

Center for Global Development, (2007). Millions saved: proven successes in global health. Center for Global Development, Washington, DC.

Chakraborty, S., (2004). Endogenous lifetime and economic growth. Journal of Economic Theory 116, 119-37.

Cigno, A., and Rosati, F.C., (1996). Jointly determined saving and fertility behaviour: Theory, and estimates for Germany, Italy, UK and USA. European Economic Review 40(8), 1561-1589.

Coate, S., (1989). Cash versus direct food relief. Journal of Development Economics 30(2): 199224.

Cunha, J.M., (2014). Testing paternalism: Cash versus in-kind transfers. American Economic Journal: Applied Economics 6(2), 195-230.

Cunha, J.M., De Giorgi, G., and Jayachandran, S., (2011). The price effects of cash versus inkind transfers. NBER Working Paper No. 17456.

Currie, J., (2009). Healthy, wealthy, and wise: Socioeconomic status, poor health in childhood, and human capital development. Journal of Economic Literature 47, 87-122.

Currie, J., and Gahvari, F., (2008). Transfers in cash and in-kind: Theory meets the data. Journal of Economic Literature 46, 333-383.

Currie, J., and Gruber, J., (1996). Health insurance eligibility, utilization of medical care, and child health. Quarterly Journal of Economics 111(2), 431-66.

Daly, G., and Giertz, F., (1972). Welfare economics and welfare reform. American Economic Review 62, 131-138.

Janvry, A., Fargeix, A., and Sadoulet, E., (1991). The political feasibility of rural poverty reduction. Journal of Development Economics 37(1-2), 351-67. 
De Waal, A., Taffesse, S., and Carruth, L., (2006). Child survival during the 2002-2003 drought in Ethiopia. Global Public Health 1(2), 125-32.

Downey, G., Purdie, V., and Schaffer-Neitz, R., (1999). Anger transmission from mother to child: a comparison of mothers in chronic pain and well mothers. Journal of Marriage and the Family 61, 62-73.

Ehrlich, I., and Lui, F., (1998). Social security, the family and economic growth. Economic Inquiry 36, 390-409.

Ehrlich, I., and Kim, J., (2005). Social security, demographic trends, and economic growth: Theory and evidence from the international experience. NBER Working Paper No. 11121.

Ehrlich, I., and Zhong, J.-G., (1998). Social security and the real economy: An inquiry into some neglected issues. American Economic Review 88(2), 151-157.

Feldstein, M., (1974). Social security, induced retirement, and aggregate capital accumulation. Journal of Political Economy 82(5), 905-926.

Fogel, R. W., (1994). Economic growth, population theory, and physiology: The bearing of longterm economic processes on the making of economic policy. American Economic Review 84, 369-395.

Gahvari, F., (1994). In-kind transfers, cash grants and labor supply. Journal of Public Economics 55, 495-504.

Galor, O., and Weil, D. N., (2000). Population, technology, and growth: from the Malthusian regime to the demographic transition and beyond. American Economic Review 90, 80628.

Garfinkel, I., (1973). Is in-kind redistribution efficient? Quarterly Journal of Economics 87, 320330.

Gertler, P., (2000). Final report: The impact of PROGRESA on health. Washington, D.C.: International Food Policy Research Institute.

Grogger, J., and Bronas, S.G., (2001). The effect of welfare payments on the marriage and fertility behavior of unwed mothers: Results from a twins experiment. Journal of Political Economy 109(3), 529-545.

Grossman, M., (1972). On the concept of health capital and the demand for health. Journal of Political Economy 80, 223-255. 
Hansson, P., and Henrekson, M., (1994). A new framework for testing the effect of government spending on growth and productivity. Public Choice 81(3-4), 381-401.

Kalemli-Ozcan, S., (2003). A stochastic model of mortality, fertility, and human capital investment. Journal of Development Economics 70, 103-18.

Keane, M., and Prasad, E., (2002). Inequality, transfers and growth: New evidence from the economic transition in Poland. Review of Economics and Statistics 84(2), 324-341.

Khera, R., (2014). Cash vs. in-kind transfers: Indian data meets theory. Food Policy 46, 116-28.

Laroque, G., and Salanie, B., (2008). Does fertility respond to financial incentives?” IZA Discussion Paper 3575.

Larson, R. W., and Gillman, S., (1999). Transmission of emotions in the daily interactions of single-mother families. Journal of Marriage and the Family 61, 21-37.

Lieber, E.M.J., and Lockwood, L.M., (2013). Costs and benefits of in-kind transfers: The case of Medicaid home care benefits. Michigan Retirement Research Center, Working Paper No. 294, University of Michigan.

Milligan, K., (2005). Subsidizing the stork: New evidence on tax incentives and fertility. Review of Economics and Statistics 87(3): 539-555.

Moffitt, R.A., (1997). The effect of welfare on marriage and fertility: what do we know and what do we need to know? Institute for Research on Poverty, Discussion Paper No. 1153-97, Johns Hopkins University.

Munro, A., (1992). Self-selection and optimal in-kind transfers. Economic Journal 102(414): 1184-96.

Neanidis, K., (2012). Humanitarian aid, fertility and economic growth. Economica, 79, 27-61.

Neanidis, K.C., and Papadopoulou, V., (2013). Crime, fertility, and economic growth: theory and evidence. Journal of Economic Behavior and Organization 91, 101-121.

Nichols, A.L., and Zeckhauser, R.J., (1982). Targeting transfers through restrictions on recipients. American Economic Review 72(2), 372-77.

Olsen, E.O., 1980. Pareto-desirable redistribution in kind: Comment." American Economic Review 70, 1028-1031.

Osang, T., and Sarkar, J., (2008). Endogenous mortality, human capital and endogenous growth. Journal of Macroeconomics 30, 1423-1445. 
Pelletier, D. L., Frongillo, E. A., and Habicht, J-P., (2003). Epidemiologic evidence for a potentiating effect of malnutrition on child mortality. American Journal of Public Health 83, 1130-1133.

Perotti, R., (1996). Growth, income distribution, and democracy: What the data say. Journal of Economic Growth 1(2), 149-187.

Philipson, T. J., and Becker, G.S., (1998). Old-age longevity and mortality-contingent claims. Journal of Political Economy 106, 551-573.

Plumber, T., and Neumayer, E., (2009). Famine mortality, rational political inactivity, and international food aid. World Development 37(1), 50-61.

Powdthavee, N., and Vignoles, A., (2008). Mental health of parents and life satisfaction of children: a within family analysis of intergenerational transmission of well-being. Discussion Paper no. 20, University of York.

Stifel, D., and Alderman, H. (2006). The "Glass of Milk" subsidy program and malnutrition in Peru. World Bank Economic Review 20(3), 421-448.

Strauss, J., and Thomas, D., (1998). Health, nutrition and economic development. Journal of Economic Literature 36, 766-817.

Zhang, J., (1995). Social security and endogenous growth. Journal of Public Economics 58(2), 185-213.

Zhang, J., and Zhang, J., (2004). How does social security affect economic growth? Evidence from cross country data. Journal of Population Economics 17(3), 473-500.

Zhang, J., Zhang, J., and Leung, M., (2006). Health investment, saving, and public policy. Canadian Journal of Economics 39, 68-93. 